\title{
Bringing data to the surface: recovering data loggers for large sample sizes from marine vertebrates
}

\author{
Karissa O. Lear ${ }^{*}$ and Nicholas M. Whitney
}

\begin{abstract}
Background: Despite the utility of data loggers for studying the fine-scale behavior and energetics of marine organisms, most studies using these tools have had relatively low sample sizes due to various factors including the logistical difficulty of physically recovering the loggers. Here, we report a simple methodology for recovering large numbers of data loggers over a broad search area, which has proven successful even for large, itinerant marine species. Techniques described include the use of VHF telemetry, a high-speed search vessel, GPS, and custom maps of the search area in order to record logger float package locations and optimize recovery strategy.

Results: We have deployed data logger packages on 193 sharks of 8 different species in the Gulf of Mexico, with a recovery rate of $97.4 \%$, retrieving 188 of the loggers with a total of over $4260 \mathrm{~h}$ of fine-scale acceleration data. Lost float packages are likely due to scavenging of sharks that succumbed to post-release mortality and ingestion of the packages by larger sharks. Mean ( \pm SD) deployment time for the packages was $22.9 \pm 22.5 \mathrm{~h}$ (range 0.7-205 h), and mean overall displacement distance was $31.3 \pm 28.2 \mathrm{~km}$ (range $0.62-231 \mathrm{~km}$ ). Animals showed a tendency to swim offshore after tagging, with $75 \%$ of packages recovered at a bearing between $180^{\circ}$ and $290^{\circ}$ relative to their tagging location. Sharks swam to deeper water after tagging, with maximum depths reaching an average of $11 \pm 8 \mathrm{~m}$ greater at the end of the track versus the start. Due to the high recovery rate and the reusability of these data loggers, we have successfully documented the post-release outcome of 188 sharks at a cost of approximately $\$ 535$ per shark, compared to a cost of $\$ 4200$ per shark to have done the same work with satellite tags.
\end{abstract}

Conclusions: Given the high recovery rate and the cost-effectiveness of these tags, our results illustrate clear advantages in cost and data quality of this method compared to studies using conventional satellite tags.

Keywords: Biologging, VHF telemetry, Accelerometry, Post-release mortality, Fisheries

\section{Background}

The use of biotelemetry and biologgers has become increasing popular in recent decades for studying the ecology and behavior of marine animals. These tools can provide a wealth of information on the behaviors and movements of free-swimming marine animals, including diving and activity patterns, habitat selection, swimming behavior, mating behavior, energy use, interaction with environmental variables, and post-capture outcomes and recovery for animals caught by fishing gear [reviewed by

*Correspondence: klear@mote.org

Behavioral Ecology and Physiology Program, Mote Marine Laboratory,

1600 Ken Thompson Parkway, Sarasota, FL 34236, USA
1-5]. These data are crucial to the successful management and conservation of many marine species, and in most cases would be impossible to obtain without the use of telemetry, especially in the marine environment where extended direct observations are limited [3, 6-8].

Historically, marine telemetry studies have mainly utilized acoustic and satellite transmitting tags. While these technologies have many advantages, studies using these types of tags are limited by factors such as the small detection range of acoustic telemetry systems $(<1 \mathrm{~km})$, the high cost of most satellite tags, and the limited bandwidth of both acoustic and the Argos satellite systems which inhibits transmission of large amounts of data [9]. 
Therefore, these types of tags generally provide only horizontal location information or depth and temperature profiles [reviewed by $9-13$ ]. These sorts of data enable researchers to track where animals go, but do not provide information about what they are doing or how they are utilizing specific habitats. As a result, the behavior and physiology of tracked animals remain unknown without the use of additional sensors, often found in the form of data-logging tags.

Data-logging tags, such as acceleration data loggers (ADLs), can record large volumes of data, including fine-scale movement and behavioral data at high sampling rates $(>30 \mathrm{~Hz})$, and store this information to memory. They are typically less expensive than satellite tags, but present the additional challenge of having to be recovered in order for the data to be obtained. Because of this limitation, their use has frequently focused on pinnipeds, seabirds, nesting turtles, or other animals that reliably return to the same terrestrial location, facilitating logger recovery [e.g., 14-16; reviewed by 7 , 8]. Data loggers have also been applied to some fish and small elasmobranchs that have a limited home range and can therefore be tracked and recaptured relatively easily to enable logger recovery [e.g., 17-21]. However, these tags have yet to reach widespread use on large, highly mobile marine species such as sharks and other top predators, because of the challenge of recovering loggers from animals that can cover large distances quickly and are difficult or impossible to recapture. A few previous studies have described data logger float package attachment mechanisms for use on large sharks, including whale sharks (Rhincodon typus, [22]), Greenland sharks (Somniosus microcephalus, [23]), tiger sharks (Galeocerdo cuvier, [24]), and white sharks (Carcharodon carcharias, [25]). However, these studies employed small sample sizes or used sharks that were generally known to remain within a recognized area or were tracked for the duration of the deployment to facilitate logger recovery.

Here, we report a simple methodology for recovering large numbers of data loggers over a broad search area that has proven successful even for large marine species capable of traveling substantial distances in a short time period. This method has enabled us to determine definitive post-release outcomes and post-release behavioral recovery data for 188 large coastal sharks caught on commercial longline fishing gear, at a fraction of the cost of doing so with satellite tags. Being able to deploy and recover these data loggers from large marine vertebrates greatly expands the potential for this technology to collect behavioral data from these animals, a task essential to informing proper management and conservation practices for animals that have high ecosystem impacts and typically readily transition through multiple habitats and regulatory zones $[26,27]$.

\section{Methods \\ Data logger attachment}

Acceleration data loggers $\left(\mathrm{G} \mathrm{A}^{+}\right.$, Cefas Technology Limited, UK) were incorporated into float packages alongside a VHF transmitter with a unique transmission frequency (MM120B, Advanced Telemetry Systems, Isanti, MN), as described by Whitmore et al. [28]. These float packages measured $12 \times 7 \times 5 \mathrm{~cm}$ and weighed $125 \mathrm{~g}$ in air, $70 \mathrm{~g}$ positively buoyant in seawater. Additionally, a small subset of larger sharks was tagged with larger float packages, which also incorporated a satellite tag to facilitate recovery. These packages included a TDR10-X ADL and SPOT-258A Argos transmitter (Wildlife Computers, Redmond, WA), and the same VHF transmitter model used in the smaller ADL packages (see above). Satelliteenabled packages were $19 \times 10 \times 5 \mathrm{~cm}$ and weighed $240 \mathrm{~g}$ in air, $75 \mathrm{~g}$ buoyant in seawater. Float packages were attached to the first dorsal fin of sharks using a tether made of plastic zip ties or monofilament with a builtin galvanic timed release (GTR; International Fishing Devices Inc., Northland, New Zealand), which corrodes in seawater after a set number of days depending on the type of GTR (Fig. 1; also see [28]). Once the GTR corroded, the package released from the shark and floated upright on the surface where the VHF tag could be detected using a handheld VHF receiver (model \#R410,

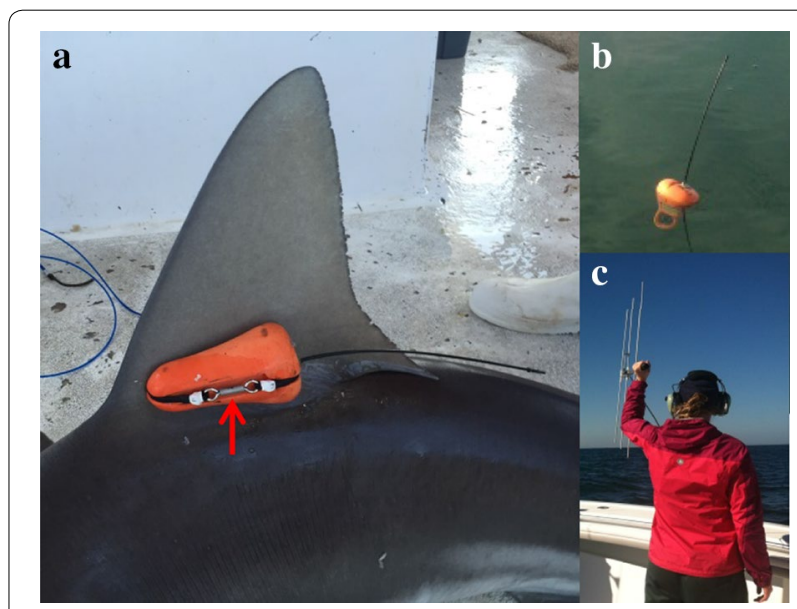

Fig. 1 Data logger float package recovery system. ADL-VHF float packages were attached to the first dorsal fin of sharks (a) using a tether with a built-in galvanic timed release (red arrow). The shark depicted here is a 222-cm TL sandbar shark (C. plumbeus). The GTR corrodes after a set amount of time and the float package detaches from the fin, floating upright on the surface $(\mathbf{b})$, so that it can be detected and tracked down using a VHF receiver (c) and recovered. See Whitmore et al. [28] for additional information on the data logger float package 
Advanced Telemetry Systems, Inc., Isanti, MN) from a minimum of 10-12 km away. The VHF float packages were set to pop off the sharks 10-72 $\mathrm{h}$ after release, while the larger float packages with incorporated satellite tags were set to pop off after 5-7 days. These packages were attached to sharks $130-350 \mathrm{~cm}$ total length caught by commercial longline gear $1-30 \mathrm{~km}$ offshore near Madeira Beach and Key West, FL (mean \pm SD distance to shore $11.79 \pm 5.58 \mathrm{~km}$ ). Seven trips were conducted from Madeira Beach and two from Key West. Between 8 and 33 sharks were tagged during each 1- to 4-day fishing trip. Shark species tagged included blacktip (Carcharhinus limbatus), sandbar (C. plumbeus), tiger (Galeocerdo cuvier), bull (C. leucas), spinner (C. brevipinna), great hammerhead (Sphyrna mokarran), scalloped hammerhead (S. lewini), and dusky sharks (C. obscurus) (Table 1). GPS waypoints were recorded at the release location of each shark.

\section{Tag recovery}

In order to ensure maximum tag recovery efficiency, recovery of the float packages was not initiated until all deployed packages were expected to have popped off the sharks. Float packages were searched for by listening for each individual package with a VHF receiver on a high-speed vessel capable of traveling large distances on a single tank of fuel (typically a 36' Yellowfin capable of traveling over $700 \mathrm{~km}$ on a tank of fuel, or a similar vessel). This vessel stopped to listen every $8 \mathrm{~km}$ while searching for packages, at which time a GPS waypoint was recorded and the location charted on a map overlaid with a latitude and longitude grid to facilitate plotting. The ID number, gain level, and approximate bearing for each package heard at the listening points were also recorded on the map in order to track multiple packages heard from different directions, and to chart out the most efficient path for recovering them. The recovery search pattern began by heading toward the tagging site and continued with directionality determined by the headings from which the nearest packages were detected. Packages were tracked down and retrieved as they were detected, and all packages at large were listened for at each recovery point. When no further packages could be detected from package retrieval points, the search pattern continued in transects reaching 30-40 km offshore of the tagging location and spaced $8 \mathrm{~km}$ apart, covering the most ground to the west and south of the tagging site. Physical ocean conditions such as current and wind direction, and in particular weed lines, which tended to aggregate drifting packages, were also used to plan and direct the search path. Stopping to listen every $8 \mathrm{~km}$ and using transects spaced $8 \mathrm{~km}$ apart to search ensured that no float packages located within the search area were missed, as the VHF signal range was typically at least $10-12 \mathrm{~km}$.

If any float packages were not detected on the first full day of tag recovery, they were searched for by plane (Cessna 172 or 182, Speed Aviation, Ft. Myers, FL) on subsequent days, as altitude enhances the range of the VHF tags [29], and a plane can cover a much greater area than a boat in a short amount of time (typical cruising speed of $150 \mathrm{mph}$ at $2500-5000 \mathrm{ft}$ ). If any of the missing packages were detected from the plane, altitude was decreased in order to better locate the signal source, and a GPS waypoint for the located package was documented and communicated to the search vessel via VHF radio, cell phone, or satellite phone. The vessel would then motor toward the given waypoint, beginning listening stops once they were within $12 \mathrm{~km}$ of the target waypoint.

Table 1 Estimated swimming displacement and bearings of tagged sharks by species

\begin{tabular}{lllllll}
\hline Species & $\begin{array}{l}\boldsymbol{n} \text { tagged (recov- } \\
\text { ered) }\end{array}$ & $\begin{array}{l}\boldsymbol{n} \text { used in displace- } \\
\text { ment analysis }\end{array}$ & $\begin{array}{l}\text { Swimming dis- } \\
\text { placement range } \\
\left(\mathbf{k m ~ d a y}^{-\mathbf{1}}\right)\end{array}$ & $\begin{array}{l}\text { Mean swimming } \\
\text { displacement } \pm \text { SD } \\
\left(\mathbf{k m}^{-1}\right)\end{array}$ & Bearing range $\left(^{\circ}\right)$ & $\begin{array}{l}\text { Mean bearing } \pm \\
\text { SD }\left(^{\circ}\right)\end{array}$ \\
\hline Blacktip & $77(75)$ & 33 & $0.5-63$ & $21^{*} \pm 15$ & $12-334$ & $219 \pm 86$ \\
Tiger & $45(44)$ & 37 & $1-55$ & $27^{* *} \pm 15$ & $7-332$ & $230 \pm 65$ \\
Sandbar & $41(41)$ & 30 & $2-72$ & $33^{* *} \pm 19$ & $149-318$ & $244 \pm 42$ \\
Spinner & $11(10)$ & 3 & $17-41$ & $29 \pm 12$ & $184-276$ & $238 \pm 48$ \\
Bull & $11(11)$ & 9 & $0.25-79$ & $27 \pm 28$ & $161-351$ & $287 \pm 78$ \\
Hammerhead & $7(6)$ & 2 & $4-5$ & $5^{*} \pm 0.4$ & $149-324$ & $236 \pm 124$ \\
Dusky & $1(1)$ & 1 & 47 & 47 & 281 & 281 \\
All Sharks & $193(188)$ & 115 & $0.25-79$ & $27 \pm 18$ & $7-351$ & $236 \pm 70$ \\
\hline
\end{tabular}

Displacement and bearing information were calculated based only on sharks that survived longline capture and were swimming for the duration of the deployment Packages that were attached to sharks for less than $6 \mathrm{~h}$ or had an estimated floating displacement greater than the total displacement were also excluded. Asterisks denote significant differences in displacement distances (Dunn test $p<0.05$ ), with blacktips and hammerheads showing shorter displacement than tiger and sandbar sharks 


\section{Data analysis}

Once the float packages were recovered, data from the ADL were downloaded and analyzed using Igor Pro (Wavemetrics, Inc., Lake Oswego, OR, USA). ADL data were used to determine whether the tagged shark survived longline capture, when the packages popped off the sharks, and depth and temperature throughout the deployments. Displacement distances and bearings between the tagging locations and package recovery locations were established using GPS coordinates from the fishing and recovery vessels.

Since it was not possible to determine precisely what percentage of displacement was attributable to animal movement versus floating displacement of the package at the sea surface, we estimated a mean floating displacement rate based on a reference data set of packages with known floating displacement rates. The reference data set consisted of satellite-enabled packages $(n=11)$, which provided locations via Argos over drift periods of 39-319 h, and VHF packages $(n=16)$, which were deployed at the surface and allowed to drift for 1-10 h before being recovered. Drift data from these packages were recorded throughout all seasons, in variable weather conditions, and in locations between 1 and $65 \mathrm{~km}$ from shore to provide an overall average floating displacement rate. The average floating displacement rate from these 27 tags was $0.45 \pm 0.18 \mathrm{~km} \mathrm{~h}^{-1}$ (mean $\pm \mathrm{SD}$ ). This value was used to calculate an estimated floating displacement for each recovered package, which was subtracted from the total displacement of the package to produce an estimated swimming displacement for tagged sharks. This method produced conservative swimming displacement estimates, as it is unlikely that the packages drifted at precisely the same heading as the sharks swam.

Mean swimming displacement distances and bearings were calculated for each species using only sharks that survived the capture process and were swimming for the duration of the deployment. Float packages that had a total displacement less than their estimated floating displacement and packages that were deployed on sharks for less than $6 \mathrm{~h}$ were also excluded from analyses. Swimming displacement rates and bearings were compared between species and between the two tagging locations with Kruskal-Wallis tests followed by Dunn's multiple comparison tests if indicated. Relationships between fish size and swimming displacement and bearing were determined using linear regressions. These analyses were conducted using the Dunn.test package in R, version 3.1.2 ( $R$ Foundation for Statistical Computing, Vienna, Austria).

\section{Cost-effectiveness calculation}

The cost-effectiveness of this accelerometer package was assessed by calculating the mean recovery cost per float package combined with the cost of the float package itself. Each ADL-VHF float package costs approximately $\$ 940$ USD (VHF $=\$ 205$, ADL $=\$ 713$, float materials $=\sim \$ 20$ ) and depending on deployment times can be reused approximately seven times based on battery life of the tag, driving float package costs down to $\$ 135$ per deployment. The mean package recovery cost, including the costs of all boats and planes involved in recovery, was combined with this $\$ 135$ tag cost to provide an approximate cost per shark for this method of assessing postrelease mortality. This cost was compared to the cost of using PSATs (pop-up satellite archival tags) to monitor post-release mortality. PSAT costs were estimated at $\$ 4200$ per shark using the Wildlife Computers PSAT at $\$ 4200$ (price does not include Argos satellite fees). Survivorship pop-up archival tags (sPATs) are a more specialized and relatively new type of archival tag that strictly provide mortality outcomes without the detailed depth and temperature data provided by PSATs. These tags cost \$2000 per shark (Wildlife Computers SPAT at \$2000 each) and were also included in cost comparisons.

\section{Results}

Package deployment and recovery

A total of 193 ADL float packages were deployed between December 2013 and August 2015. Of these, 188 have been recovered, for a $97.4 \%$ recovery rate. Deployment times ranged between 0.7 and $62.2 \mathrm{~h}$ for VHF packages (mean $\pm \mathrm{SD}, 22.9 \pm 22.5 \mathrm{~h}$ ) and 12-205 h for the larger, satellite-enabled packages (mean $53 \pm 57 \mathrm{~h}$ ). Float packages were recovered between 0.62 and $231 \mathrm{~km}$ from the tagging locations, at a mean distance of $31.3 \pm 28.2 \mathrm{~km}$, and were detected via VHF receiver from up to $25 \mathrm{~km}$ away, though detection range was generally decreased in severe weather and near electrical storms. Packages were typically found in loose clusters, with $82 \%$ of packages recovered within $10 \mathrm{~km}$ of another package. Tag recovery effort lasted between 1 and 5 days depending on tag recovery success, but was generally completed within 3 days (Fig. 2). Seventy-four percent of float packages were recovered on the first full day of tag recovery, with $51 \%$ recovered within $24 \mathrm{~h}$ of releasing from the shark.

Of the float packages not found during our recovery efforts, $55 \%$ (6 out of 11) later washed up on beaches and were found and returned by beachgoers; three within 1 month; and all 6 within 5 months after deployment. Five of these six returned packages were on sharks that succumbed to post-release mortality and were scavenged and the packages eaten (evident in their acceleration traces, Fig. 3) preventing them from floating to the surface. Scavenging of float packages by large predators (presumably sharks) was observed in $16 \%$ of sharks that succumbed to post-release mortality. Of blacktip and 


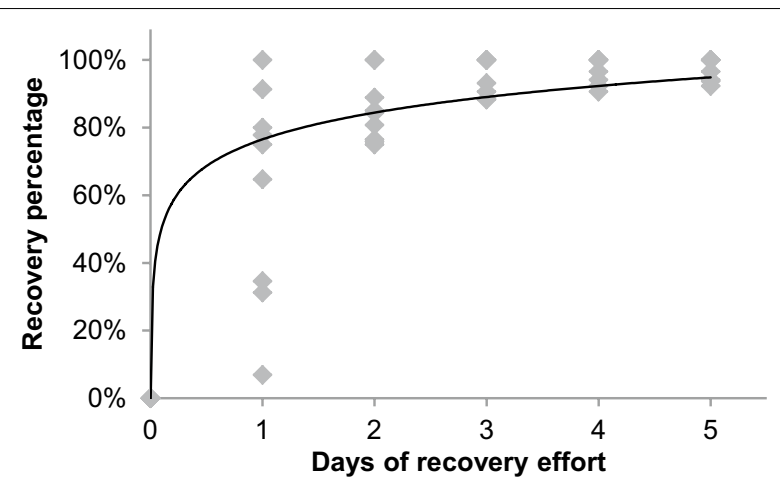

Fig. 2 Cumulative package recovery percentage by day throughout the recovery process ( $n=9$ trips). Recovery for all trips was completed within five recovery days

spinner shark packages not found during initial recovery efforts, $54 \%$ had been scavenged. All scavenged packages were ingested between 3.5 and $24 \mathrm{~h}$ after the shark died $(10.5 \pm 8.14 \mathrm{~h}$, mean $\pm \mathrm{SD})$, and most were regurgitated by the scavenger between 2 and 6 days later (mean
$4.65 \pm 1.56$ days), though one was not regurgitated until 30 days after ingestion. Of the five remaining unrecovered packages, four were VHF packages that were never detected during the recovery process. The fifth unrecovered package was a larger, satellite-enabled package, deployed on a $2.7 \mathrm{~m}$ tiger shark for 5.5 days. This package popped off the shark $225 \mathrm{~km}$ offshore and was not recovered.

\section{Drift patterns}

Drift patterns from the reference drift dataset showed that short-term surface movement of packages was haphazard, with drifting packages often looping around to return to near their previous locations. However, during multi-day periods with constant weather patterns, longer-term drift patterns were generally consistent with wind-wave direction measured by nearby NOAA weather buoys. This suggests that during periods of consistent weather, wind and wave direction can be a useful tool in predicting drift patterns of float packages; however, in more variable weather conditions package drift direction is not reliably predictable.

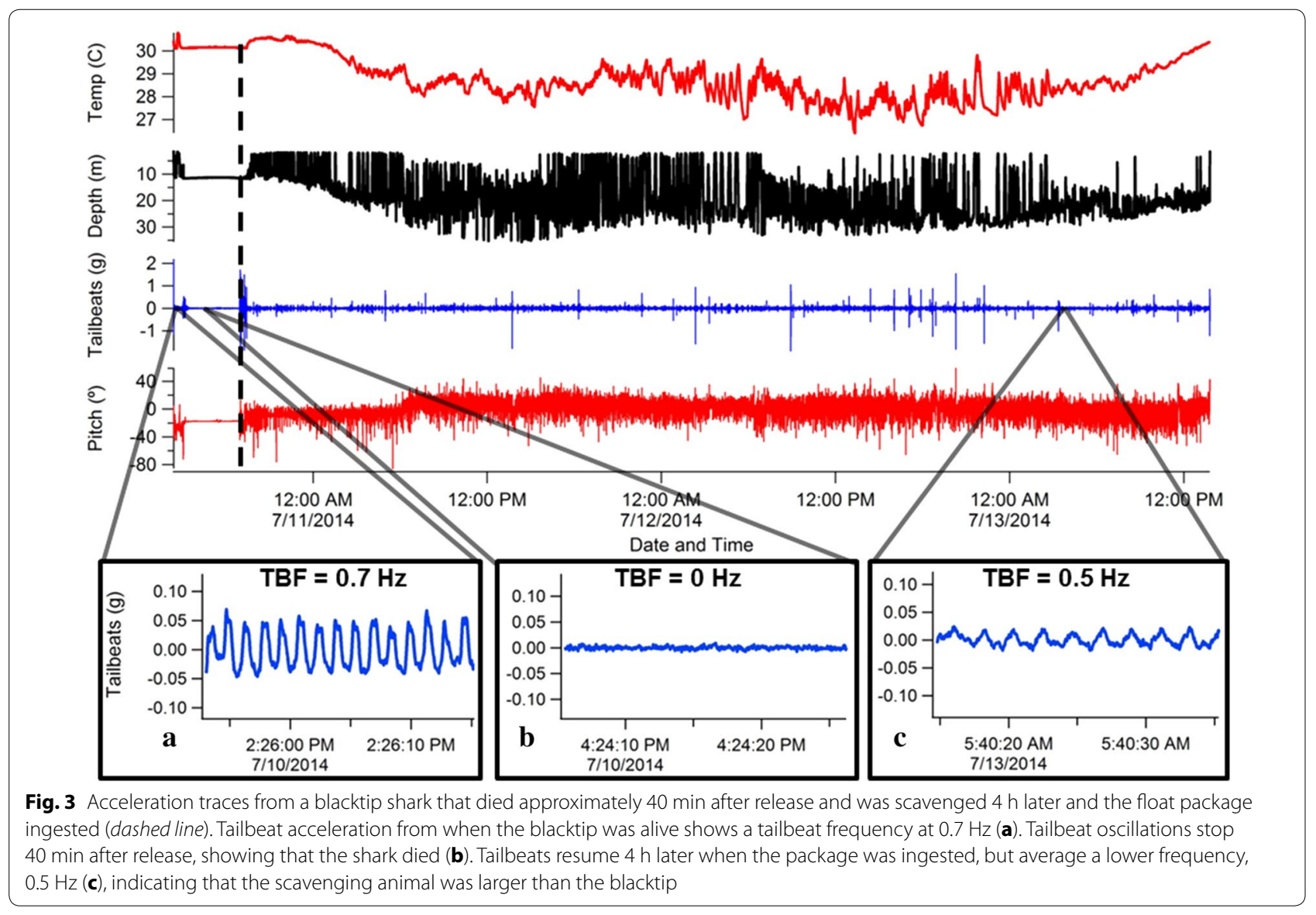




\section{Post-release displacement}

Sharks that survived the effects of longline capture tended to swim at similar headings after release, largely directed offshore and to the south of the tagging site, with $75 \%$ of packages recovered at a bearing between $180^{\circ}$ and $290^{\circ}$ relative to the tagging location (Fig. 4). Tagging location (Madeira Beach or Key West, FL) did not significantly affect bearing (Kruskal-Wallis $\chi^{2}=0.0005$, $p=0.98, d f=1$ ). Fish size also did not affect bearing (linear regression $F=0.798, p=0.374, R^{2}=0.007, d f=108$ ). Mean bearings for each species between the tagging and package recovery locations ranged from $219^{\circ}$ to $287^{\circ}$, with an overall mean bearing of $236^{\circ}$ (Table 1). There were no significant differences in bearings between species (Kruskal-Wallis $\chi^{2}=6.65, p=0.35, d f=6$ ). Congruent with the offshore swimming patterns observed from float package recovery locations, $93 \%$ of sharks showed greater maximum depths in the last hour of deployment compared to the first hour, with depths a mean of $11 \pm 8 \mathrm{~m}$ greater in the last hour of deployment. However, temperature did not necessarily decrease with depth throughout the deployment. Instead, $48 \%$ of tagged sharks showed higher water temperatures in the last hour of deployment compared to the first hour, a pattern seen exclusively during winter months when offshore water temperatures are higher than shallow water temperatures (Fig. 5).

While post-release bearing did not differ significantly between the species studied, there were significant differences in the displacement distance per day between species (Kruskal-Wallis $\chi^{2}=19.12, p=0.004, d f=6$ ). Mean displacement distances for species ranged from 5 to $33 \mathrm{~km} \mathrm{day}^{-1}$, with blacktips and great hammerheads having significantly lower displacement distances than tiger and sandbar sharks (Dunn test $p<0.05$ ) (Table 1). Tagging location did not have a significant effect on displacement distance (Kruskal-Wallis $\chi^{2}=2.85, p=0.09$, $d f=1)$. Overall fish size was also not significantly correlated with swimming displacement distance (linear regression $\left.F=2.043, p=0.1558, R^{2}=0.019, d f=108\right)$, though this relationship was significant within blacktip sharks alone $\left(F=6.83, p=0.015, R^{2}=0.28, d f=26\right)$.

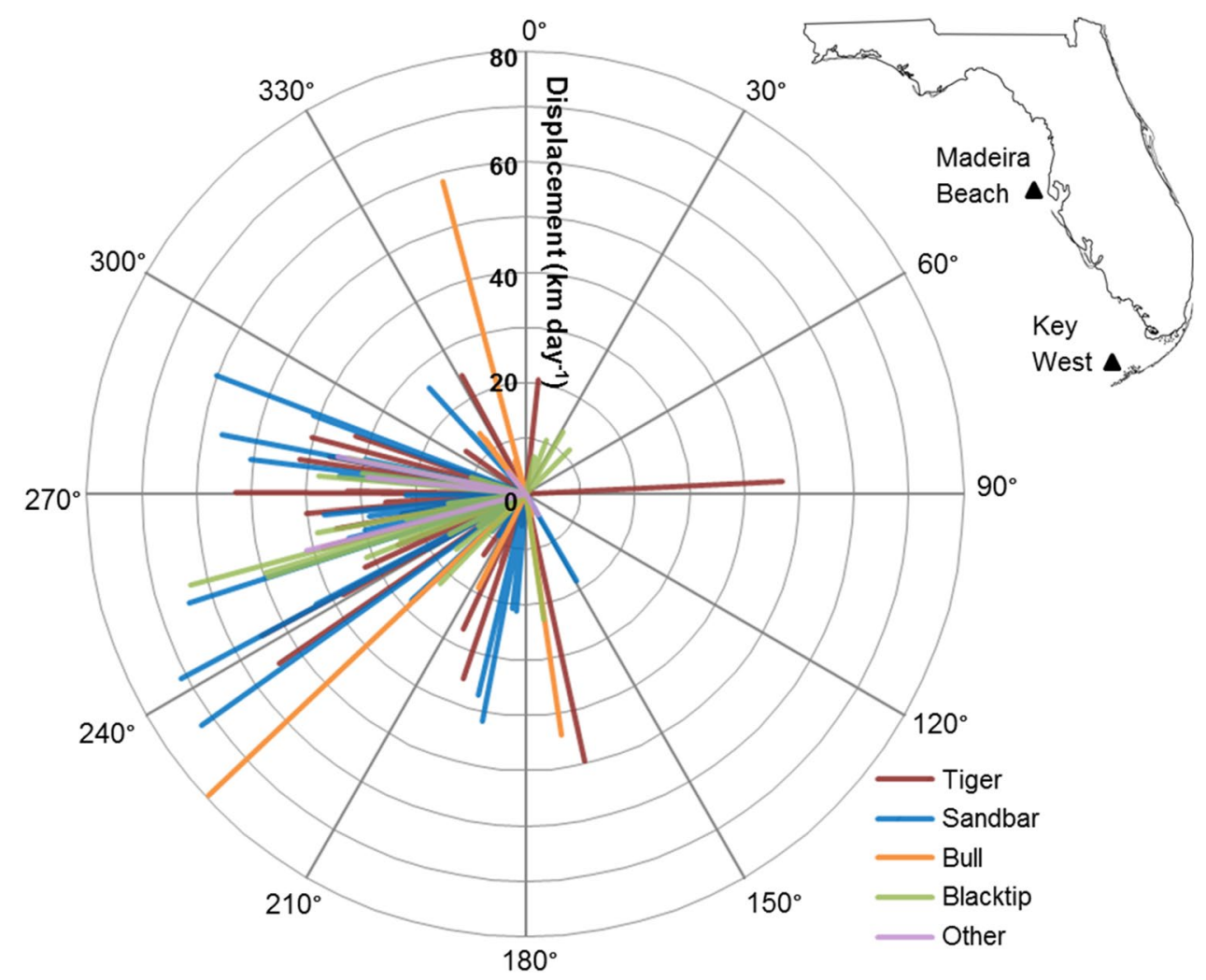

Fig. 4 Bearings and estimated swimming displacement distances $\left(\mathrm{km}^{-1}{ }^{-1}\right.$ ) between shark tagging locations (triangle, Madeira Beach and Key West, FL) and package recovery locations for individual sharks that survived longline capture $(n=115)$. Deployments where the estimated floating displacement was greater than the total displacement or where packages were attached to sharks for $<6 \mathrm{~h}$ were not included. Sharks tended to travel offshore (west) and south of where they were tagged, with $75 \%$ of float packages found between a bearing of $180^{\circ}$ and $290^{\circ}$ relative to where they were deployed, regardless of tagging location or time of year 

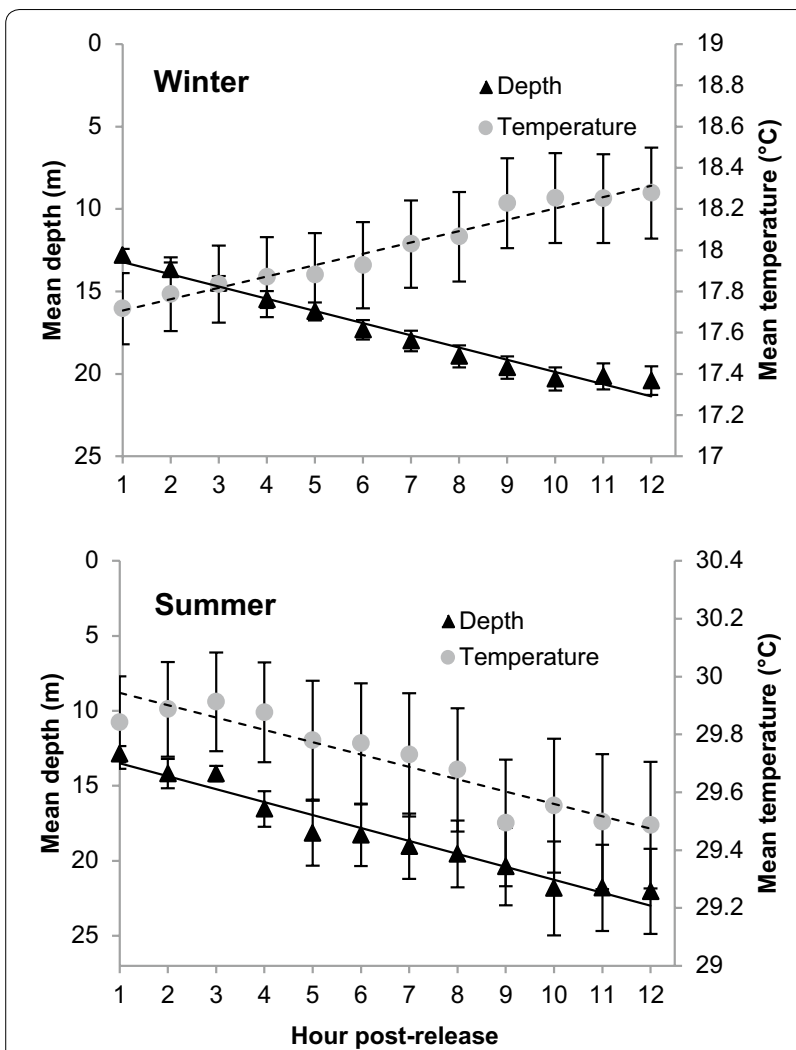

Fig. 5 Mean depths and temperatures for all tagged sharks for the first $12 \mathrm{~h}$ post-release in winter (December-March, water temperatures below $20^{\circ} \mathrm{C}, n=65$ ), and summer (May-October, water temperatures $29-31^{\circ} \mathrm{C}, n=59$ ). Sharks typically swam into deeper water after release regardless of time of year; however, this was not related to finding cooler water, as mean temperatures increased in deeper water during the winter time. Error bars show standard deviation

Estimated drift displacement of the packages did not differ between species (Kruskal-Wallis $\chi^{2}=7.43, p=0.28$, $d f=6)$.

\section{Cost-effectiveness of ADL tagging and recovery method} Cost-effectiveness of the ADL tagging method increased when more sharks were tagged during a trip (Fig. 6). Recovery vessels traveled a mean of $320 \pm 50 \mathrm{~km}$ on full recovery days and typically cost between $\$ 1200$ and $\$ 1800$ per day (mean $\$ 1528 \pm \$ 368$ ) depending on mileage and fuel costs. Search planes travelled around $470 \mathrm{~km}$ per day, were typically used for 1-2 days of recovery during each trip, and generally cost between $\$ 700$ and $\$ 2000$ per day, again depending on mileage and fuel costs (mean $\$ 1235 \pm \$ 649$ ). Recovery costs, including all boat and plane costs, averaged $\$ 400$ per shark, which combined with the tag cost of $\$ 135$ per deployment produce an overall cost of $\$ 535$ per shark for this technique (Fig. 6).

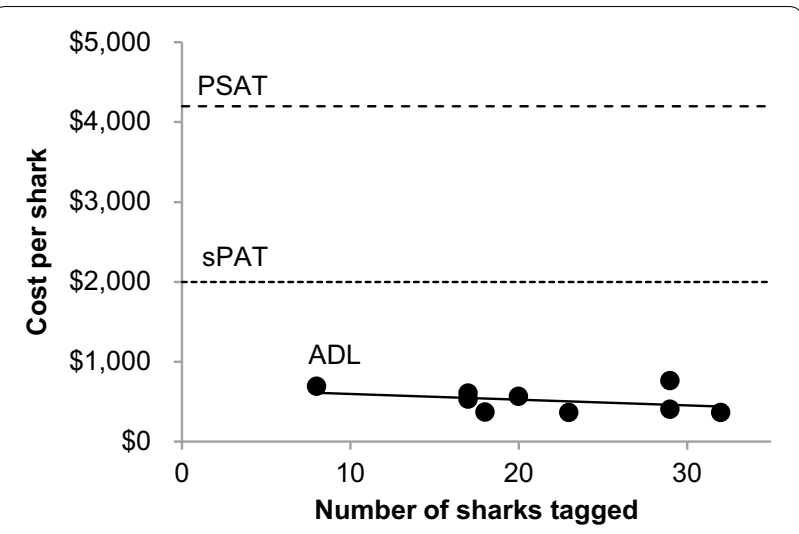

Fig. 6 Costs of ADL tagging and recovery method per trip ( $n=9$ trips) compared with costs of PSAT and SPAT tagging methods. The $A D L$ tagging and recovery is typically more cost-effective on trips where greater numbers of sharks are tagged. Overall ADL cost per shark averaged $\$ 535$ including tag and recovery costs, compared to $\$ 4200$ for PSATs and $\$ 2000$ for sPATs

\section{Discussion}

This ADL float package recovery method proved a successful system for recovering data loggers, maintaining over a $97 \%$ recovery rate for 193 tags deployed on large marine predators in open water. Although some ADLs were not recovered, our recovery rate is higher than the data recovery rate in many shark satellite tag studies, where an average of $10 \%$ of deployed tags can fail to transmit data [12].

\section{Post-release behavioral patterns}

Additionally, the post-release swimming patterns and displacement rates described here are helpful in understanding sharks' reactions to capture stress and interspecific differences in post-release behavior, as well as assisting with float package recovery. Sharks of all species almost exclusively swam offshore and to deeper water after longline capture and tagging. This offshore swimming behavior mirrors results found in active tracking studies, where sharks typically swam toward deeper water and offshore of the tagging locations after longline or hook-and-line capture [30-34]. Although cooler water temperatures may facilitate aerobic recovery due to higher oxygen content and reduced stress responses in cooler temperatures [35-40], the tendency of sharks to seek deeper water did not always lead to them swimming in cooler water. This offshore-directed swimming behavior may instead be indicative of a flight response in reaction to capture and handling or may represent animals seeking a preferred temperature range for recovery that is cooler than surface waters in the summer and warmer than surface waters in the winter. 
While sharks of all species tended to swim in the same general direction after release, their displacement rates varied by species. These differences in displacement cannot simply be attributed to fish size, as overall fish size was not significantly correlated with swimming displacement. Instead, these displacement patterns may stem from differences in behavior and life history between species or indicate relative susceptibility to capture stress, with the more robust sandbar and tiger sharks swimming further than blacktips and hammerheads, which show higher vulnerability to capture stress $[39,41,42]$.

The slow tailbeat frequencies shown in acceleration data retrieved from packages that were eaten (Fig. 3) indicate that scavenging species are typically larger than the animals that were originally tagged. Ingested packages tend to remain inside the stomach of the scavenger for at least a few days prior to regurgitation. Thus, packages that have been ingested are typically not found during the regular recovery efforts, as they may still be inside the scavengers during recovery, or have been carried outside of the recovery search area.

In addition to providing information about postrelease behavior, species-specific post-release displacement patterns proved helpful in locating and recovering float packages that were not found in the first stage of tag recovery, allowing us to postulate possible locations for the packages based on the species that had carried the package. For instance, missing packages deployed on tiger, sandbar, and bull sharks (species with greater average travel distances) were likely located outside of the initial search area, whereas missing blacktip, spinner, and hammerhead shark packages (species that showed higher vulnerability to capture stress and typically had shorter travel distances) were more likely to have been ingested by a scavenger.

This scavenging scenario is a probable explanation for the four unrecovered VHF float packages, deployed on blacktip, spinner, and hammerhead sharks, species that all show high vulnerability to capture stress and may have died after release. Other possibilities include failure of the VHF transmitter, damage to the float package that prevented it from floating upright at the surface, or unusual long-distance swimming by the tagged animal that carried the package out of the search area.

\section{Cost-effectiveness of ADL tagging and recovery method}

Given the high recovery rate, the relatively low costs of data logger tags, and the reusability of these tags, this tagging and recovery method has also proven extraordinarily costeffective compared to other methods of assessing postrelease mortality and behavior of sharks. This ADL tagging technique costs an average of $\$ 535$ per shark compared to $\$ 4200$ per shark for PSAT methods (excluding Argos charges), or $\$ 2000$ per shark for sPATs. Thus, this method can assess acute post-release mortality of sharks and other large highly and vagile marine species at approximately $1 / 8$ th the cost of doing the same work with traditional PSATs, or around $1 / 4$ th the cost of using sPATs, while at the same time delivering finer-scale behavioral data than satellite tags offer, providing opportunities for robust sample sizes in post-release or other behavioral research and greatly enhancing the statistical power of these studies.

Although this float package and recovery method has proved highly successful, this technique offers shorter deployment durations than satellite tags. Recovery rates may also be reduced in remote areas without access to high-speed vessels and planes, although these tools are not essential for successful package recovery. The majority of float packages were recovered on the first few days of recovery effort without aerial telemetry assistance.

\section{Conclusions}

The large sample size, high ADL recovery rate (97\%), and low cost compared to traditional satellite tagging studies (1/4th to $1 / 8$ th the cost of satellite tags) demonstrate the effectiveness of this float package and recovery method for short-term behavioral studies on large marine species, and particularly studies investigating post-release mortality. The ability to reliably recover these ADL float packages greatly expands the field of use for biologging tools on large, mobile marine species and also enhances the conservation potential for this technology. Fine-scale behavioral data such as those recorded by ADLs can provide a wealth of knowledge about swimming dynamics, energy expenditure, and recovery from capture, among other behavioral parameters, which is essential to providing a clear understanding of the ecology of these animals and to properly informing management and conservation measures. With the application of this ADL recovery system, it is possible for the first time to collect this type of data from large numbers of coastal predators that have substantial impacts on their ecosystems, are often vulnerable to overfishing, and are typically data poor species.

\section{Abbreviations}

ADL: acceleration data logger; VHF: very high frequency; PSAT: pop-up satellite archival tag; sPAT: survivorship pop-up archival tag; TL: total length.

\section{Authors' contributions}

NMW conceived the study; KOL carried out the fieldwork, refined the technique, and performed the analyses. Both authors read and approved the final manuscript.

\section{Acknowledgements}

We would like to thank J. Morris, G. Schweiterman, and A. Ontkos for their assistance with aerial telemetry and fieldwork. Mote Marine Operations captains D. Dougherty, G. Byrd, C. Jelicks, and P. Hull, and pilots G. Roam, F. Casey, and J. Powell were also essential to successful tag recovery, as were 
various Behavioral Ecology and Physiology Program interns. We thank A. Gleiss, B. Whitmore, and C. White for assistance in developing the tag float package and $\mathrm{H}$. Marshall for providing feedback on the manuscript and assisting with fieldwork.

\section{Competing interests}

The authors declare that they have no competing interests.

\section{Availability of data and material}

Source material and data are available upon request.

\section{Ethics approval}

This work was approved by the Mote Marine Laboratory Institutional Animal Care and Use Committee, protocol \# 13-11-NW2.

\section{Funding}

This work was funded through National Oceanic and Atmospheric Administration Grants from the Bycatch Reduction and Engineering Program (Grants \#NA13NMF4720274 and \#NA14NMF4720320) and the Cooperative Research Program (Grant \#NA13NMF4540056), and a Waitt Foundation Rapid Ocean Conservation Grant.

Received: 10 February 2016 Accepted: 18 April 2016

Published online: 06 May 2016

\section{References}

1. Block BA. Physiological ecology in the 21 st century: advancements in biologging science. Integr Comp Biol. 2005;45:305-20.

2. Bograd SJ, Block BA, Costa DP, Godley BJ. Biologging technologies: new tools for conservation. Introduction. Endang Species Res. 2010;10:1-7.

3. Brown DD, Kays R, Wikelski M, Wilson R, Klimley P. Observing the unwatchable through acceleration logging of animal behavior. Anim Biotelem. 2013:1:20

4. Cooke SJ, Hinch SG, Wikelski M, Andrews RD, Kuchel LJ, Wolcott TG, et al. Biotelemetry: a mechanistic approach to ecology. Trends Ecol Evol. 2004;19:334-43.

5. Whitney NM, Papastamatiou YP, Gleiss AC. Integrative multisensor tagging: emerging techniques to link elasmobranch behavior, physiology, and ecology. In: Carrier JC, Musick JA, Heithaus MR, editors. Biology of sharks and their relatives. 2nd ed. Boca Raton: CRC Press; 2012. p. 265-89.

6. Cooke SJ. Biotelemetry and biologging in endangered species research and animal conservation: relevance to regional, national, and IUCN Red List threat assessments. Endang Species Res. 2008;4:165-85.

7. Ropert-Coudert Y, Wilson RP. Trends and perspectives in animal-attached remote sensing. Front Ecol Environ. 2005;3:437-44.

8. Wilson RP, Shepard ELC, Liebsch N. Prying into the intimate details of animal lives: use of a daily diary on animals. Endang Species Res. 2008:4:123-37.

9. Sims DW. Tracking and analysis techniques for understanding free-ranging shark movements and behavior. In: Carrier JC, Musick JA, Heithaus MR, editors. Sharks and their relatives II: biodiversity, adaptive physiology, and conservation. Boca Raton: CRC Press; 2010. p. 351-92.

10. Arnold G, Dewar H. Electronic tags in marine fisheries research: a 30-year perspective. In: Silbert JR, Nielson JL, editors. Electronic tagging and tracking in marine fisheries. Amsterdam: Springer; 2001. p. 7-64.

11. Costa DP, Breed GA, Robinson PW. New insights into pelagic migration: implications for ecology and conservation. Annu Rev Ecol Evol Syst. 2012;43:73-96.

12. Hammerschlag N, Gallagher AJ, Lazarre DM. A review of shark satellite tagging studies. J Exp Mar Biol Ecol. 2011;398(1):1-8.

13. Hart KM, Hyrenbach D. Satellite telemetry of marine megavertebrates: the coming of age of an experimental science. Endang Species Res. 2009;10:9-20.

14. Burger AE, Shaffer SA. Application of tracking and data-logging technology in research and conservation of seabirds. Auk. 2008;125(2):253-64.

15. Williams TM, Fuiman LA, Horning M, Davis RW. The cost of foraging by a marine predator, the Weddell seal Leptonychotes weddellii: pricing by the stroke. J Exp Biol. 2004;207:973-82.
16. Yoda K, Naito Y, Sato K, Takahashi A, Nishikawa J, Ropert-Coudert Y, Kurita $M$, Le Maho Y. A new technique for monitoring the behavior of freeranging Adelie penguins. J Exp Biol. 2001;204:685-90.

17. Clark TD, Sandblom E, Hinch SG, Patterson DA, Frappell PB, Farrell AP. Simultaneous biologging of heart rate and acceleration, and their relationships with energy expenditure in free-swimming sockeye salmon (Oncorhynchus nerka). J Comp Physiol B. 2010;180:673-84.

18. Tanaka H, Takagi Y, Naito Y. Swimming speeds and buoyancy compensation of migrating adult chum salmon Oncorhynchus keta revealed by speed/depth/acceleration data logger. J Exp Biol. 2001;204:3895-904.

19. Tsuda Y, Kawabe R, Tanaka H, Mitsunaga Y, Hirashi T, Yamamoto K, Nashimoto K. Monitoring the spawning behaviour of chum salmon with an acceleration data logger. Ecol Freshw Fish. 2006;15:264-74.

20. Whitney NM, Papastamatiou YP, Holland KN, Lowe CG. Use of an acceleration data logger to measure diel activity patterns in captive whitetip reef sharks, Triaenodon obesus. Aquat Living Resour. 2007;20:299-305.

21. Whitney NM, Pratt HLJ, Pratt TC, Carrier JC. Identifying shark mating behaviour using three-dimensional acceleration loggers. Endang Species Res. 2010;10:71-82.

22. Gleiss AC, Norman B, Liebsch N, Francis C, Wilson RP. A new prospect for tagging large free-swimming sharks with motion-sensitive data-loggers. Fish Res. 2009;97:11-6.

23. Watanabe Y, Lydersen C, Fisk AT, Kovacs KM. The slowest fish: swim speed and tail-beat frequency of Greenland sharks. J Exp Mar Biol Ecol. 2012;426-427:5-11.

24. Nakamura I, Watanabe YY, Papastamatiou YP, Sato K, Meyer CG. Yo-yo vertical movements suggest a foraging strategy for tiger sharks Galeocerdo cuvier. Mar Ecol Prog Ser. 2011;424:237-46.

25. Chapple TK, Gleiss AC, Jewell OJD, Wikelski M, Block B. Tracking sharks without teeth: a non-invasive rigid tag attachment for large predatory sharks. Anim Biotelem. 2015;3:14.

26. Musick JA, Burgess G, Cailliet G, Camhi M, Fordham S. Management of sharks and their relatives (Elasmobranchii). Fisheries. 2000;25:9-13.

27. Techera EJ, Klein N. Fragmented governance: reconciling legal strategies for shark conservation and management. Mar Policy. 2011;35:73-8.

28. Whitmore BM, White CF, Gleiss AC, Whitney NM. A float-release package for recovering data-loggers from wild sharks. J Exp Mar Biol Ecol. 2016:475:49-53.

29. Gilmer DS, Cowardin LM, Duval RL, Mechlin LM, Shaiffer CW, Kuechle VB. Procedures for the use of aircraft in wildlife biotelemetry studies. U.S. Fish and Wildlife Service; 1981

30. Afonso AS, Hazin FHV. Post-release survival and behavior and exposure to fisheries in juvenile tiger sharks, Galeocerdo cuvier, from the South Atlantic. J Exp Mar Biol Ecol. 2014;454:55-62.

31. Carey FG, Scharold JV. Movements of blue sharks (Prionace glauca) in depth and course. Mar Biol. 1990;106:329-42.

32. Heithaus MR, Wirsing AJ, Dill LM, Heithaus LI. Long-term movements of tiger sharks satellite-tagged in Shark Bay, Western Australia. Mar Biol. 2007:151:1455-61.

33. Holland KN, Wetherbee BM, Lowe CG, Meyer CG. Movements of tiger sharks (Galeocerdo cuvier) in coastal Hawaiian waters. Mar Biol. 1999; 134:665-73.

34. Holts DB, Bedford DW. Horizontal and vertical movements of the shortfin mako shark, Isurus oxyrinchus, in the Southern California Bight. J Mar Freshw Res. 1993:44:901-9.

35. Braccini M, Van Rijn J, Frick L. High post-capture survival for sharks, rays and chimaeras discarded in the main shark fishery of Australia. PLoS One 2012;7:e32547.

36. Danylchuk AJ, Suski CD, Mandelman JW, Murchie KJ, Haak CR, Brooks $A M L$, et al. Hooking injury, physiological status and short-term mortality of juvenile lemon sharks (Negaprion brevirostris) following catch-andrelease recreational angling. Conserv Physiol. 2014;2:127-33.

37. Gallagher AJ, Orbesen ES, Hammerschlag N, Serafy JE. Vulnerability of oceanic sharks as pelagic longline bycatch. Glob Ecol Conserv. 2014;1:50-9.

38. Hoffmayer ER, Hendon JM, Parsons GR. Seasonal modulation in the secondary stress response of a carcharhinid shark, Rhizoprionodon terraenovae. Comp Biochem Physiol A. 2012;162:81-7.

39. Morgan A, Burgess GH. At-vessel fishing mortality for six species of sharks caught in the Northwest Atlantic and Gulf of Mexico. Gulf Caribbean Res. 2007;19:123-9. 
40. Skomal G, Bernal D. Physiological responses to stress in sharks. In: Carrier JC, Musick JA, Heithaus MR, editors. Sharks and their relatives II. Boca Raton: CRC Press; 2010. p. 459-90.

41. Mandelman JW, Skomal GB. Differential sensitivity to capture stress assessed by blood acid-base status in five carcharhinid sharks. J Comp Physiol B. 2009;179:267-77.
42. Gallagher AJ, Serafy JE, Cooke SJ, Hammerschlag N. Physiological stress response, reflex impairment, and survival of five sympatric shark species following experimental capture and release. Mar Ecol Prog Ser. 2014:496:207-18.
Submit your next manuscript to BioMed Central and we will help you at every step:

- We accept pre-submission inquiries

- Our selector tool helps you to find the most relevant journal

- We provide round the clock customer support

- Convenient online submission

- Thorough peer review

- Inclusion in PubMed and all major indexing services

- Maximum visibility for your research

Submit your manuscript at www.biomedcentral.com/submit
() Biomed Central 